\title{
Portunhol: a intercompreensão em uma língua da fronteira
}

\author{
Eliana Rosa Sturza (D) @ \\ Universidade Federal de Santa Maria (UFSM), Brasil
}
Neste mundo tan yeio de imposición
Fueron pasando los año
Y eu miorei meu español Mas nunca perdí las gana
De gritar por rebelión
Insistiendo por u recreio Pa' abraza meu portunhol.
(Lingua Mae)

Resumo. A dinâmica da vida nas comunidades fronteiriças do Brasil - Uruguai e do Brasil - Argentina tem favorecido o contato linguístico entre o português e o espanhol. O portunhol surgiu como uma língua de contato, que se caracteriza como uma língua familiar e como prática comunicativa usada pelos falantes para suas interações em diversas práticas sociais da vida cotidiana. Neste texto, trata-se do portunhol uruguaio e do portunhol língua da fronteira como práticas comunicativas usadas para atender às necessidades imediatas de comunicação, como se estruturam e como funcionam pelo grau de intercompreensão estabelecido entre as duas línguas. O portunhol se relaciona, ainda, à identidade dos fronteiriços e à valorização da cultura local.

Palavras-chave: fronteira; portunhol; intercompreensão; língua de contato.

\section{Portuñol: la intercomprensión en una lengua de frontera}

Resumen. La dinámica de la vida en las comunidades fronterizas de Brasil - Uruguay y de Brasil - Argentina ha favorecido el contacto linguístico entre el portugués y el español. El portuñol surge como una lengua de contacto que se caracteriza como una lengua familiar y como una práctica comunicativa usada por los hablantes para sus interacciones en diversas práticas sociales de la vida cotidiana. En este texto, se trata del portuñol uruguayo y el portuñol lengua de frontera como práticas comunicativas usadas para atender a las necesidades inmediatas de comunicación, de como se estructuran y de como funcionan por el grado de intercomprensión establecido entre las dos lenguas. Además, el portunhol se relaciona con la identidad de las fronteras y la apreciación de la cultura local. Palabras clave: frontera; portunhol; intercomprensión; lengua de contacto.

\section{Portunhol: the inter-understanding in a border language}

Abstract. The dynamics of life in the border communities of Brazil-Uruguay and Brazil-Argentina has favored the linguistic contact between portuguese and spanish. Portunhol emerged as a contact language that is characterized as a familly lenguage and as communicative practice used by speakers for their interactions in various social practices of everyday life. In this text, we refer to the uruguayan portunhol and to the portunhol border language as communicative practices used to meet the immediate needs of communication, how they are structured and how they function by the degree of inter-understanding established between the two languages. The portunhol is also related to the identity of the frontiers and the appreciation of the local culture.

Keywords: frontier; portunhol; intercomprehension; contact language. 


\section{Introdução}

O poema da epígrafe, de autoria do grupo musical uruguaio Lingua $M_{a e^{1}}$ exemplifica o quanto as línguas têm um componente de identificação dos falantes com o território e com a cultura. A língua estabelece um elo de pertença do sujeito ao seu espaço de vivência e convivência que, em se tratando das zonas de fronteira, tem suas especificidades.

Camblong (2002) destaca que há um modo de viver e habitar a fronteira. Os sujeitos fronteiriços expressam seu sentimento de pertença em relação ao que é da ordem local, ou seja, a uma zona comum que abarca um conjunto de traços diacríticos sobre os quais são construídos os vínculos de pertencimento. 0 sentido identitário da língua para os habitantes de comunidades fronteiriças, como as localizadas na fronteira Brasil - Uruguai e/ou Brasil-Argentina, relaciona-se ao modo como os fronteiriços se reconhecem e como atuam politicamente. Reconhecem-se como habitantes de uma zona territorial do nem lá nem cá. A dinâmica da vida na fronteira os torna "únicos", tal como declara uma uruguaia da cidade de Rivera, entrevistada no documentário Língua Imaginária. ${ }^{2}$ A construção de uma identidade fronteiriça, como por exemplo, as dos dobles chapas ${ }^{3}$, caracteriza-se por ser, ao mesmo tempo, binacional, courbada e "entreverada". Nessa condição social, histórica, cultural e política destaca-se uma língua: o Portunhol.

O contato linguístico entre o português e o espanhol na América do Sul produziu o portunhol como uma prática comunicativa usada pelos fronteiriços em situações específicas e para determinados propósitos. Deste modo, é uma língua que tem falantes, mas não tem ainda uma gramática estável, nem há uma regularidade na construção linguística de suas formas. Esse contato linguístico, tem sido tema de pesquisas em diferentes perspectivas teóricas. (Albuquerque, 2014; Barrios, 2014; Fenner \& Corbari, 2014; Lipiski, 2011; Maia \& Méndez, 2017; Sturza, 2006, 2019).

As zonas de fronteira, ao longo dos seus territórios limítrofes, do extremo sul ao norte do Brasil, apresentam uma diversidade e complexidade social, política e linguística. Neste sentido, cada comunidade tem uma história, uma formação social e cultural e uma confluência de línguas. Nessas zonas, o uso do portunhol é mais recorrente, em especial, nas comunidades

${ }^{1}$ Lingua Mae, Editorial Independiente, 2015. Rafael Andreazza.

2 Língua Imaginária, Produção Maviola filmes, direção de Cíntia Langie e

3 Doble chapas são chamados os fronteiriços uruguaios-brasileiros com dupla nacionalidade. Refere-se ao fato de os carros terem durante um período duas placas de identificação, uma brasileira e uma uruguaia. 
fronteiriças nas quais há um maior fluxo de pessoas e onde as relações são mais intensas e favorecidas pelo tipo de fronteira existente: fronteiras secas, menos controladas e mais urbanizadas.

Neste artigo, darei destaque ao portunhol praticado pelos falantes que vivem nas cidades gêmeas ou em pequenas comunidades localizadas nas fronteiras do Brasil com Argentina e do Brasil com o Uruguai, que são fronteiras reconhecidamente com maior densidade demográfica, e que fazem parte do chamado Arco Sul. ${ }^{4}$ As fronteiras localizadas no Arco Sul são mais povoadas, com cidades gêmeas ${ }^{5}$ ao longo da sua extensão, como Santana do Livramento-Rivera ou Uruguaiana - Paso de Los Libres. 0 acesso facilitado por meio de estradas, pontes e balsas, que realizam a travessia para o "outro lado", é um fator que contribui para aumentar o fluxo de pessoas, estabelecendo-se um trânsito contínuo nas fronteiras. Embora haja o controle aduaneiro e migratório, o tipo de fronteira, e como ela se organiza, favorece os deslocamentos migratórios e as trocas, os intercâmbios e os negócios no nível local, é uma relação cotidiana transnacional. O maior número de cidades gêmeas nessa faixa de fronteira do Arco Sul permite discutir e exemplificar situações de uso do portunhol uruguaio e o portunhol língua da fronteira como dois fenômenos linguísticos, resultado do contato entre falantes de português e de espanhol, que impulsionam as dinâmicas sociais, econômicas, políticas e culturais na/da fronteira.

O contato e a mistura das línguas constituem o portunhol, condição que nos possibilita debater também a sua funcionalidade nas interações comunicativas. Enquanto uma prática linguística e comunicativa, a mistura é potencializada pela intercompreensão construída a partir da proximidade linguística entre as duas línguas. Além disso, a intercompreensão também se torna mais efetiva à medida que verificamos a existência de uma gama de identificações culturais, dada pelo nível de convivência entre os falantes de português e espanhol e pelas práticas sociais nas quais o portunhol funciona de modo a responder às demandas de interação social requeridas no dia a dia. Para abordar sobre essa intercompreensão, é necessário levantar duas questões: pra quais propósitos de comunicação pretendido os falantes recorrem ao portunhol e não ao português ou espanhol? Com que recorrência os falantes se apoiam nas semelhanças linguísticas entre as duas línguas para subsidiar sua competência comunicativa garantindo assim um grau de intercompreensão?

\footnotetext{
${ }^{4}$ Refere-se às fronteiras da região sul do Brasil, de acordo com as definições e os mapas desenvolvidos para a Proposta de Reestruturação do Programa de Desenvolvimento da Faixa de Fronteira, Ministério da Integração Nacional, 2005.

${ }^{5}$ Cidades gêmeas são cidades que se correspondem em relação às suas localizações nos limites territoriais, estão de um lado e de outro na fronteira.
} 
As questões levantadas aqui surgem pela observação de que o portunhol se estabiliza cada vez mais como uma língua da fronteira. Somase a isso, a reivindicação do portunhol como patrimônio cultural no Uruguai reforçando uma luta pelo reconhecimento da cultura fronteiriça, que passa também pelo reconhecimento da língua.

\section{Portunhol: que língua é essa?}

O portunhol é uma prática linguística e comunicativa, que tomo aqui como língua considerando que há falantes e, cada vez mais, apresentase como um traço da construção identitária para seus falantes, em especial, no caso do portunhol uruguaio. É uma língua que, se não tem ainda um sistema linguístico regular e estável, tem certamente um sistema interacional e comunicativo vigoroso, dado a eficácia que apresenta em determinadas práticas sociais: um anúncio em um estabelecimento comercial, a descrição de um lugar, uma sinalização ou instrução, um cardápio de restaurante, uma negociação de preços, um pedido de reserva de hotel, uma identificação pessoal, entre outras tantas práticas comunicativas que são realizáveis em portunhol e que dinamizam a vida na fronteira.

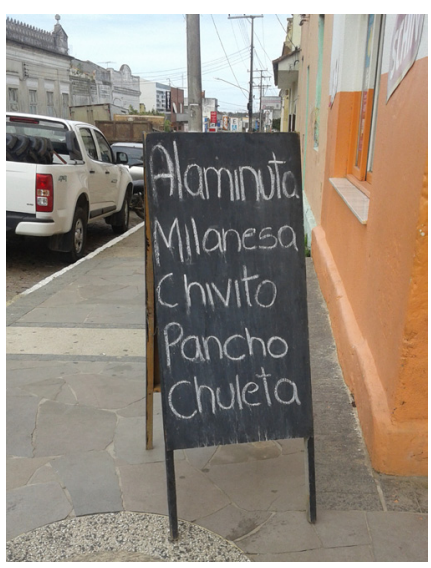

Fuente: foto da autora - $2014^{6}$

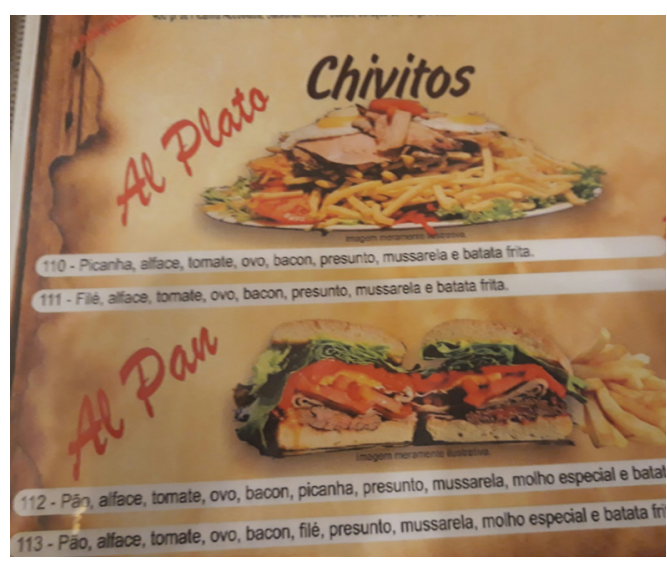

Fuente: foto da autora - $2018^{7}$

No entanto, com objetivo de descrever a importância e o funcionamento do portunhol como uma língua da e na fronteira, faz-se necessário diferenciar o portunhol língua da fronteira do que se está designando como

${ }^{6}$ Cidade Jaguarão, fronteira Brasil - Uruguai.

${ }^{7}$ Cidade Quaraí, fronteira Brasil - Uruguai. 
portunhol uruguaio. Nas figuras acima, observa-se o uso alternado das duas línguas em uma mesma materialidade textual, mais recorrente no lado brasileiro da fronteira. Os cardápios alternam os nomes das comidas e de seus ingredientes, evidentemente na busca de comunicar de modo mais claro o que oferecem como pratos nos estabelecimentos gastronômicos. 0 gesto de fazê-lo, alternando as duas línguas, mostra como elas estão presentes no mesmo espaço que são frequentados por brasileiros e/ou uruguaios e argentinos, há nesse gesto um propósito comunicativo relevante para a convivência na fronteira. Os cardápios impressos ou expostos ao público constroem paisagens linguísticas únicas sobre o funcionamento do portunhol como língua da fronteira.

Os gestos dos fronteiriços demonstram atitudes que podem ser positivas ou negativas em relação ao uso das duas línguas ou da "mistura", tal como costumam nomeá-la ao descrever o modo como falam. 0 portunhol usado do lado brasileiro da fronteira pode ser reconhecido pela maneira como se mistura o espanhol no português, não provoca mudanças na estrutura linguística, mas bastante interferências verificadas nas escolhas lexicais, na entonação e pronúncia dos falantes. Há uma linha de difícil percepção que diferencie, pelo menos do ponto vista dos falantes imersos no mundo da fronteira, se eles estão falando portunhol ou apenas alternando o uso das duas línguas nas suas conversas. É fato que usam as línguas de modo a alternálas de acordo com o interlocutor, se falante de espanhol ou se falante de português, porém se apoiam na mistura como estratégia interacional, sempre e quando a comunicação requer uma efetividade. Para ilustrar, descrevo a seguinte cena na fronteira Brasil - Uruguai ${ }^{8}$

Hotel na cidade Quarai (Brasil) fronteira com Artigas (Uruguai). A hóspede que acaba de chegar pergunta: um lugar para cenar? Recepcionista responde: para jantar aqui enfrente tem restaurante. E acrescenta: el desayuno das $7 \mathrm{~h}$ as 10h.. Me aproximo e pergunto ao recepcionista se os uruguaios não falam português e ele me responde: a gente ajuda. Insisto se os uruguaios não falam português com eles quando chegam ao hotel. Ele acrescenta: Portunhol, porque português bem mesmo...eles não falam.

O recepcionista reconhece a relação do portunhol uruguaio com o português do Uruguai, no entanto destaca a funcionalidade da mistura para essa situação de uso, que resolve a comunicação entre ele e os hóspedes uruguaios.

${ }^{8}$ Nota registrada pela autora na cidade Quaraí - Brasil, fronteira com a cidade Artigas - Uruguai, 2018. 
O portunhol uruguaio tem diferenças significativas em relação ao portunhol língua de fronteira, que seriam: uma relação histórica, de herança com o português brasileiro; um sistema diglóssico que contribui para a manutenção do portuñol/fronterizo como língua de casa, em disputa com o espanhol; um estigma que marca seus falantes frente o "status social" do português padrão e do espanhol, línguas de prestígio e, por último, o fato de que cada vez mais se constitui em uma língua étnica dos fronteiriços do norte uruguaio, portanto com vínculos identitários, que remetem a um lugar de pertença e a uma cultura fronteiriça.

O relato do escritor fronteiriço uruguaio Severo (2015) mostra claramente que o uso do portunhol uruguaio está relacionado ao ambiente familiar, aprendido com os pais, falado por uma população marginalizada por sua condição econômica, suas origens e seu fracasso escolar. 0 mudo "intreverado" é uma experiência de conflito linguístico:

Yo nací na cidade de Artigas. Mi familia, mis vecino y mis amigo, falan misturando las palabra del portugués y el español. El portuñol es mi língua materna. Cuando yo istava na barriga de mi madre, ya iscutaba el mundo intreverado. Despós, na época que hice la iscuela, me quiseron hacer creer que los que hablábamo misturado éramos pobre, sucios, burros. ${ }^{9}$

O conflito lingüístico ocorre na disputa entre a língua do âmbito familiar e a língua nacional, a que a escola impõe como língua da alfabetização, tal como relata Fabián Severo e que aparece também no poema do Lingua Mae, na epígrafe. Não é só a percepção dos falantes, pois os estudos de Barrios (2014) apontam que se criou um estigma em relação ao falante de portunhol uruguaio, relacionando-o a pouca escolarização, à pobreza, muitos falantes vivem no campo ou são oriundos de zonas rurais e, hoje em dia, também nas periferias das cidades. Falar misturado é visto como um mal falar.

A ocupação política e econômica de luso-brasileiros na região norte do Uruguai, mais sistemática a partir do final séc. XVIII, contribui para expandir e fixar a presença do português em território uruguaio. A hegemonia da cultura lusa e brasileira na região resultou em uma variedade de português que predominou como língua das famílias, sobretudo no meio rural e em localidades até cerca de $200 \mathrm{~km}$ para dentro do território uruguaio. Essa situação instituiu um sistema diglóssico entre um português do Uruguai (PU) e o espanhol. 0 espanhol passou a marcar sua presença como língua do Estado nacional no final século XIX, através de uma política educacional e linguística, que a instituiu como língua obrigatória e única na instrução escolar.

9 https://bit.ly/2ZXb98L 
Atualmente, os documentos oficiais que orientam a educação pública uruguaia reconhecem a situação linguística da fronteira e destacam os efeitos dessa política educacional e linguística a partir da Ley de instrucción Pública, de José Pedro Varela, de 1877: "Esta política educativo-linguística fue seguida al pie de la letra en todo el territorio y, especialmente, en la frontera, donde los lusohablantes que la poblaban casi exclusivamente fueron aculturados desde entonces a partir del modelo de los hispanohablantes del sur." $(2008)^{10}$

A presença do português na região norte do Uruguai e seu contato com o português foi pesquisada por (Rona, 1965; Elizaincín, Barrios \& Behares, 1987; Hensey, 1972; Carvalho, 2003). O resultado deste contato linguístico recebeu respectivamente o nome de: Fronterizo, Portuñol/Fronterizo, Dialectos Portugueses del Uruguay (DPUs) e Português do Uruguai (PU). No entanto, nas últimas décadas tem se fortalecido o nome de portunhol, em lugar das designações atribuídas até então por esses pesquisadores. Barrios (2014) aborda sobre as denominações de variedades em contato, afirmando que:

La denominación de una variedad en situaciones de contacto adquiere particular relevancia porque involucra contiendas de adscripción; puede destacar el vínculo con una lengua de base (como "portugués uruguayo" o "dialectos portugueses del Uruguay"), su condición de mezcla entre las lenguas en contacto (como "portuñol") o ser relativamente independiente en ambos sentidos (como "dialecto fronterizo" o "fronterizo"). Puede adecuarse al estatus lingüístico que le asignan los investigadores o a las experiencias comunitarias, pero siempre contribuye a la conformación de representaciones y actitudes linguísticas. (Barrios, 2014, p.77)

Sturza (2006) os relaciona com as perspectivas metodológicas e as teorias linguísticas que predominaram na designação da língua de contato. No entanto, observa-se que atualmente os falantes passaram cada vez mais a designá-la de portunhol, o que os linguistas descreveram e nomearam como DPU e/ou PU. A respeito do que significa falar portunhol para os fronteiriços do norte uruguaio, em entrevista ao jornalista João Vicente Ribas, publicada no jornal do Comércio em 2019, o poeta, tradutor e dramaturgo Michel Croz chama atenção:

existem muitos portunhóis. O falado em um bairro não é o mesmo de outro. O portunhol de Artigas difere do encontrado em Bagé ou em Jaguarão. "A sua beleza intocada se dá pelo fato de que ainda não pode ser direcionado - as palavras não têm dicionário, ou uma gramática. Ainda bem!",

${ }^{10}$ Documentos de la Comisión de las Políticas Linguísticas en la Educación Pública. Administración Nacional Pública, Consejo Directivo Central, Montevideo, 2008. 
comemora Croz. Para ele, o portunhol é uma língua dos afetos, que se fala para comunicar no presente, resgatando o passado. "Há uma tradição forte, mas que se impulsa para o futuro".

A "língua dos afetos" está na relação do portunhol uruguaio com sua história, com o ambiente familiar e, portanto, remete a uma população que se reconhece pela língua. 0 portunhol uruguaio tem apelo afetivo por seu uso social e sua relação com a cultura fronteiriça, de origem luso-brasileira, que quer se diferenciar de outras regiões do país. Há visivelmente uma mudança cultural na sociedade fronteiriça em busca de valorização do Portunhol.

Neste sentido, Barrios (2014) afirma que:

Un término como "portuñol", interpretado como peyorativo o descriptivamente incorrecto por su alusión a la condición de mezcla, no deja de ser interesante para reflejar la simbiosis cultural de las comunidades de frontera. La representación "ni una cosa ni la otra" podría también interpretarse como "las dos cosas al mismo tiempo"; si es así, una denominación que no se identifique totalmente con una sola lengua podría ser adecuada para simbolizar una identidad particular y autónoma. Si la población acepta una denominación que remite a una identidad de mezcla, la estigmatización de esa denominación desde el propio ámbito académico podría tener un efecto negativo, ya que se podría interpretar que la mezcla es en sí misma algo inaceptable. Si esto ocurre, las consecuencias podrían ser tan negativas como las que se pretende evitar. (Barrios, 2014, p.102)

Para além de ser língua materna de muitos uruguaios do norte, e de que a "mezcla" pode ou não ser aceitável como língua, o portunhol uruguaio se aproxima ao portunhol língua da fronteira à medida que ambos só puderam se constituir pela mistura entre português e o espanhol nas condições sócio-históricas que se deram. Português e espanhol são duas línguas com um espectro de semelhanças bastante amplo e suas intersecções são também intensificadas pela situação de vizinhança geográfica. Ambos portunhóis constituem comunidades de fala que convivem nos mesmos espaços, dominados pelas línguas nacionais, nos quais os falantes buscam se adequar às necessidades comunicativas e, assim, melhorar seus níveis de compreensão, inclusive para identificar a relevância pragmática que orienta suas conversas diárias, regulares, contínuas.

\section{Intercompreensão e a proximidade linguística}

Entre as definições do que é o portunhol há, bastante difundida no Brasil, a do portunhol como interlíngua, que é um sistema linguístico que se produz durante o processo de aprendizagem do espanhol por parte 
de aprendizes brasileiros (ou vice-versa). A característica dessa interlíngua está na sua especificidade como um fenômeno de contato linguístico que ocorre em situações de aprendizagem, em diferentes contextos e níveis de aprendizagem. Mais do que uma etapa, para Selinker (1991, p.83-84) a interlíngua é um terceiro sistema linguístico independente, no qual o aluno busca ser eficiente no uso da norma da língua objeto, ou seja, da língua que está aprendendo.

Na perspectiva das teorias de aprendizagem de línguas, o foco é o aprendiz e o ensino da língua, não o propósito da comunicação imediata e cotidiana como aquele necessário para os falantes fronteiriços, tampouco o do uso do portunhol uruguaio como uma língua étnica. Como língua da fronteira, por exemplo, o falante brasileiro lança mão do portunhol como uma estratégia de comunicação que Ihe ajuda interagir com argentinos e uruguaios e ser assim compreendido. 0 portunhol interlíngua no processo de aprendizagem se relaciona às fases de aquisição, é um estágio que o aprendiz passa ao aprender a língua objeto, quando escolhe obter um nível de proficiência em português ou espanhol como língua estrangeira ou, quando está imerso no contexto de uso, sendo ela português ou espanhol.

Nos estudos sobre ensino de espanhol no Brasil, portunhol como designação para ocorrência de interlíngua surge com o objetivo de dar conta de nomear a fase em que os aprendizes ainda misturam a norma das duas línguas, caracteriza-se pelas dificuldades apresentadas pelos aprendizes brasileiros em aprender espanhol, considerando que essas línguas apresentam sistemas linguísticos aproximados, às vezes facilitando, outras vezes dificultando o aprendizado. 0 grau de interferências linguísticas do português na fala dos aprendizes de espanhol advém da ênfase nas falsas semelhanças, nomeadas inclusive como "falsos amigos". Pautado pela análise contrastiva, esse enfoque fortalece o lugar hegemônico de duas línguas nacionais no imaginário do aprendiz, em geral por ter como meta alcançar a proficiência de um falante nativo, portanto, nessa perspectiva, as línguas não devem ser confundidas ou misturadas. Dominar a norma da língua materna e da segunda língua (língua objeto) como ideal parece estar em consonância com o contexto no qual havia o predomínio de visões monolíngues, muito associadas às políticas nacionalistas do século XX. Sendo assim, a interlíngua, nessa visão, mais que ser uma fase no processo de aprendizagem, configura-se em um "problema", normalmente associado ao "erro".

Em abordagens mais contemporâneas, destaca-se o portunhol interlíngua como um "recurso", entendido como um fenômeno normal no processo de aprendizagem. As interferências são compreendidas como naturais pelos contatos que se produzem entre o português e o espanhol, mas levando em conta também as experiências linguísticas já trazidas pelo aprendiz, e que 
são condizentes com as características deste mundo contemporâneo, no qual as fronteiras linguísticas se tornam mais fluídas, ou seja, de algum modo todos somos translíngues. Autores como Zolin-Vesz (2014) defendem que

pensar o Portunhol como translíngua envolve considerar o movimento entre as fronteiras linguísticas do português e espanhol, ou seja, envolve um "aprender movendo-se", uma vez que essas fronteiras linguísticas em sala de aula, exponencialmente, se tornam mais fluídas e porosas, maximizadas pela proximidade entre as ambas as línguas. (Zolin-Vesz, 2014, p.327)

Identifica-se no portunhol interlíngua que a questão do contato linguístico é tratada no contexto do ensino e apresenta assim duas posições pedagógicas: a que coloca ênfase no aspecto negativo da Interlíngua, em razão do grau de interferências do português ou espanhol (língua materna dos aprendizes) no processo de aprender a língua alvo (o espanhol ou português como língua segunda ou estrangeira), e aquela que considera esses processos como naturais da sociedade contemporânea em que as línguas estão mais presentes na vida dos sujeitos, tendo eles um propósito bem estabelecido de aprender outra língua ou simplesmente porque já têm incorporado no seu repertório linguístico experiências com outras línguas, fazendo com que essa "vantagem" se reverta em um recurso para aprender uma segunda língua, processos ou sistemas intermediários são parte do aprendizado.

O portunhol interlíngua traz para discussão a proximidade das línguas, a natureza do contato e sua relação com o erro e com falar mal uma das línguas. Tradicionalmente quando se trata de portunhol tem-se reforçado a ideia da interlíngua. Porém, em outros contextos nos quais a vivência e imersão nas duas línguas se potencializa, portunhol é um recurso para as demandas de interação como as que ocorrem na sociedade fronteiriça, por isso é fundamental discutir as diferenças de seus funcionamentos para cada contexto de uso. Sturza (2019) identifica quatro ocorrências: portunhol uruguaio, portunhol língua da fronteira, portunhol interlíngua e portunhol selvagem.

Reafirma-se que o portunhol é uma prática linguística de valor interacional nas diferentes práticas sociais dos falantes que vivem e habitam nas fronteiras geopolíticas entre o Brasil, Argentina e Uruguai ${ }^{11}$. É uma língua que os falantes recorrem pelo potencial de intercompreensão que se produz nas trocas, nas tarefas e agendas da vida cotidiana; tem forte apelo interacional e só possível entre as duas línguas. 0 portunhol mostra-se eficiente para as situações cotidianas de interação como já foi exemplificado.

${ }^{11}$ Fronteiras às quais me refiro nos exemplos mencionados e que constituem o recorte das pesquisas realizadas. 
A intercompreensão que é construída no uso da língua de contato respond formaçãe às necessidades imediatas e são favorecidas de acordo com a natureza das relações sociais desenvolvidas entre os falantes fronteiriços. É preciso compreender o que significa a intercompreensão enquanto constitutiva nao de uma língua de contato, as condições sociais em que ela se origina, no tipo de relação que os falantes produzem ao alternar ou misturar as duas línguas.

A questão que conduz a reflexão aqui apresentada não se refere aos processos formais de aprendizagem de uma língua. Deste modo, proponho tomar como referência as práticas sociais nas quais o portunhol se constitui como uma língua de interação comunicativa, como forte circulação local bem como por constituir-se em apelo identitário para os falantes que habitam as zonas fronteiriças. 0 portunhol é tomado pelo falante como ponto de partida para que ela seja melhor compreendido, utiliza-se da semelhança das línguas, que potencializa, amplia e fortalece a comunicação imediata, dinamizada as relações cotidianas, que são inclusive transnacionais. Outra questão que se levanta é: a proximidade das duas línguas românicas, de formações gramaticais de mesma linhagem, não seria uma vantagem na interação social e na integração entre as comunidades fronteiriças? Não haveria de se impulsionar as vantagens da proximidade em lugar de temer a fossilização de formas e usos errôneos? Ou ainda considerarmos então que todos estamos integrados aos movimentos e trânsitos do mundo globalizado?

Para discutir esta proposta de ol har sobre o portunhol, associando-o a um espaço de funcionamento da intercompreensão em lugar de cunhá-lo como nome de uma Interlíngua, gerada inconvenientemente pelo contato, os exemplos das situações de comunicação estabelecidas na vida cotidiana dos fronteiriços nos subsidiam para debater quais características e em que práticas sociais a intercompreensão está na base que estrutura o portunhol como uma língua da fronteira. Em relação ao portunhol uruguaio, sendo a base linguística predominantemente portuguesa, certamente, é uma vantagem para dinamizar a comunicação entre os fronteiriços, do lado de cá e de lá da fronteira.

Capucho (2010) ao abordar a Intercompreensão, ainda como um tema da Didática das Línguas, afirma que:

A Intercompreensão (IC) é, como o afirmava recentemente Jean-Pierre Chavagne (2009: 1), uma prática ancestral e um fenómeno recente. Reportada numa tradição secular de práticas comunicativas entre habitantes de regiões limítrofes ou inserida nas vivências dos viajantes de todos os tempos, a IC foi recuperada há cerca de vinte anos por investigadores no 
âmbito da Didáctica das Línguas, da Linguística Aplicada, da Sociolinguística, da Psicolinguística ou da Linguística Contrastiva, para referir apenas as disciplinas mais frequentemente solicitadas. (Capucho, 2010, p.102)

Destaco da sua afirmação, o fato de mencionar a intercompreensão como "práticas comunicativas de regiões limítrofes", ou seja, antes de ser o foco de uma abordagem didática, a intercompreensão tem seu funcionamento observado nas interações entre falantes de "regiões limítrofes", quer dizer, em zonas de fronteiras geopolíticas. Pois, a intercompreensão ocorre nas identificações e semelhanças que línguas aparentadas possuem e que servem para alavancar a aprendizagem de uma delas: um falante brasileiro pode ter como ponto de partida um grau de intercompreensão do espanhol que o leve a aperfeiçoar sua proficiência na língua espanhola.

Em entrevista ao jornalista João Vicente Ribas, publicada em 21 de julho de 2019, no jornal do Comércio ${ }^{12}$, o historiador Eduardo Palermo, sintetiza a funcionalidade do portunhol uruguaio nas relações cotidianas,

Se tu perguntar a um uruguaio aqui em Rivera qual o idioma que ele fala, ele irá dizer espanhol, ou talvez o português; não dirá que fala portunhol", garante. Mas repara que, no cotidiano, é o portunhol que se fala mais. "As pessoas falam da melhor forma possível para se comunicar, sem que se pense nisso.

Essa "melhor forma possível para se comunicar" evidencia-nos que, dentro do repertório linguístico que os fronteiriços uruguaios dispõem, a escolha pelo portunhol ocorre por uma percepção, como a do historiador, que os falantes fronteiriços uruguaios optam pela "mistura" para as dinâmicas do cotidiano. Desta forma, confirma-se o que o cantor riverense Chito de Mello defende nas suas músicas, ao dizer que é um "rompidiomas" porque canta "misturado".

"Entender e se fazer entender" é a pauta que determina as trocas cotidianas nas interações comunicativas feitas em Portunhol. Na sua dissertação de mestrado Coutinho (2016) mapeia a presença do espanhol nos anúncios de estabelecimentos comerciais na cidade de Uruguaiana. Em registro fotográfico desses anúncios, a autora mostra como o espanhol está presente na fronteira brasileira pelo uso de palavras que são compreendidas nas duas línguas, ainda que com alterações ortográficas. Tal presença está marcada no uso recorrente dos artigos definidos El e La do espanhol, de modo a especificar e particularizar o nome do estabelecimento, em um gesto de aproximação: La Campeira, La fronteira; El turco; La Fiambreria, La Whisqueria, El gordo, entre outros exemplos.

12 https://bit.ly/2YYR30C 
Se há uma base de português no portunhol uruguaio, no portunhol língua de fronteira há uma significativa presença de palavras e expressões do espanhol no chamado português gaúcho da fronteira (PFG) (Trindade, Brehares \& Fonseca, 1995). No lado brasileiro se incorporam ao português palavras sobretudo relativas à vida rural, à lida campeira, às tradições culturais. No "Dicionário Compartilhado de Língua de Fronteira"13 (2015), elaborado por estudantes de escolas da cidade de Itaqui, na fronteira Brasil-Argentina, há um número considerável de léxicos do espanhol, como: chancho, entrevero, remolacha, aragano, avil, paisano, xisme, churipã, que tal, a la pucha. Outro conjunto vem do Minidicionário do Uruguaianês, de autoria de Lourival Araújo Gonçalves, publicado no livro "A terra de longos olhares" (2005), organizado por Lucia Silva e Silva. Entre algumas palavras do "castellano" estão: abombado, al pedo, alambrado, apucherado, boludo, borracho, buenas, bueno, buenacho.

Uma pesquisa de Henriques (2000) enfocando a intercompreensão na leitura de textos escritos por parte de falantes brasileiros, aprendizes de espanhol, a autora resume:

Como mostramos, existe um alto grau de intercompreensão entre os falantes de ambas as línguas, em relação à: (1) compreensão de textos (já que esses falantes podem usar estratégias de inferência lexical para ajudá-los na compreensão global do texto); (2) tradução (já que existe um alto índice de palavras cognatas idênticas e não-idênticas); e (3) inferência de itens lexicais (com a ajuda de estratégias de vocabulário e de gramática). (Henriques, 2000, p.29).

As considerações de Henriques (2000) mostram um número significativo de léxicos comuns que impulsionam a compreensão na leitura de textos. Pensemos sobre as pautas que organizam a vida fronteiriça e certamente se identificará nelas um conjunto de léxicos, como os mencionados acima, relativos a uma cultura transfronteiriça compartilhada e que significam nas e pelas dinâmicas da fronteira, e não se repetem em outros lugares, facilitando assim a comunicação entre brasileiros, argentinos e uruguaios.

Na fronteira Brasil-Argentina, há também pesquisas que abordam a presença do português do lado argentino da fronteira, e como o contato linguístico com o espanhol impulsionou a existência de uma mescla linguística, chamada de portunhol. Este é o caso do portunhol falado em comunidades localizadas nos limites territoriais do Brasil com as províncias de Corrientes e de Missiones. Nesse caso, o deslocamento de brasileiros durante meados

13 Este dicionário (dois volumes) foi elaborado por alunos das duas escolas do município de Itaqui, fronteira Brasil-Argentina, participantes do Programa Escolas Interculturais de Fronteira, antigo Projeto Escolas Interculturais Bilingues de Fronteira. 
do século XX para outro lado da fronteira, para exploração da erva mate, da madeira e também para cultivo de arroz e soja, colocou em contato não só falantes de português como também falantes de alemão (teuto-brasileiros), de russo, de polonês com falantes de espanhol e guarani, em comunidades localizadas em Posadas, ou em comunidades localizadas às margens do rio Uruguai, como El Soberbio e Oberá.

Tal como no norte uruguaio, o português nessas regiões se manteve como língua familiar e, em contato com o espanhol, produziu uma mescla, identificada pelos falantes como brasilero ou portuñol. Maia \& Méndez (2017, p.160) nomeiam esse português como português missioneiro de fronteira (PMF), e esclarece que "O PMF, para os informantes é uma mistura, é não falar bem o português. Algumas delas utilizam como sinônimo a palavra brasilero. Reconhecem que é uma versão do português, com um pouco de mistura do espanhol."

O documentário dirigido por Ana Zanotti Escenas de la vida en el borde, a seção "Mixtura de Vidas", gravado na colônia Santa Rita, no lado argentino da fronteira, província de Missiones, a docente da escola da comunidade comenta que os estudantes, filhos ou netos de brasileiros, chegam à escola falando português e que, aos poucos vão incorporando o "castellano", que há muita mistura das línguas, e destaca que: "En el patio siguen hablando su idioma, entre comillas, en "portuñol".

Destaca-se que ambas regiões de fronteira, Brasil-Uruguai e BrasilArgentina, o deslocamento de brasileiros para outro lado da fronteira, contribuiu para a instauração de um sistema, no mínimo diglóssico, o português como língua familiar, com menos status social, e o espanhol como língua de prestígio, usado para as atividades mais formais. O portunhol, funciona como uma língua de entremeio nesse sistema diglóssico.

O quadro de exemplos e dos estudos referidos nos mostram a necessidade de investir em mais pesquisas sobre o contato português e espanhol na América do Sul. O portunhol como uma língua de contato, é a língua da fronteira, determinada pelas dinâmicas da vida e da cultura fronteiriças, que se intensificam pela capacidade dos falantes de se comunicarem, de interagirem. No entanto, não temos estudos descritivos que mostrem quais mudanças linguísticas ocorrem na formação da mistura das línguas, se há uma tendência de regularidade na estrutura linguística que resulta no portunhol, se é uma terceira língua. Temos indícios do seu funcionamento para determinadas práticas sociais, porém não se tem certeza se este é seu limite. 
Vale ressaltar que na fronteira Brasil-Argentina amplia-se o repertório linguístico, os fronteiriços dispõem do: português, espanhol, alemão, guarani e mais o portunhol, ou seja, um quadro mais plurilíngue, em oposição à fronteira Brasil-Uruguai que tende a manter seu potencial para o bilinguismo.

\section{Considerações finais}

Para responder às questões levantadas inicialmente, buscou-se realizar um percurso panorâmico sobre o contato linguístico nas fronteiras Brasil-Argentina, Brasil-Uruguai, enfocando o funcionamento tanto do portunhol uruguaio como do portunhol língua da fronteira.

Os exemplos apresentados mostram, por um lado, a percepção dos falantes sobre a relação do portunhol com uma identidade e cultura de fronteira, com características, inclusive, transnacionais. Essa relação se pauta no reconhecimento de um modo de falar que não é nem português nem espanhol, mas que tem funcionado para as relações cotidianas, sustentadas em um grau de intercompreensão que coloca os falantes em uma dinâmica, impulsiona as interações sociais, de modo que se efetivem plenamente, em especial, em certas práticas sociais. Seria necessário descrever e ampliar as pesquisas que venham a mapear quais práticas sociais o portunhol funciona, mas também quais ele não é efetivo para a comunicação entre falantes de português e de espanhol.

Por outro lado, há indícios importantes sobre a constituição da "mistura". Ainda que existam escolhas aleatórias no falar o portunhol, há estratégias comunicativas que podem auxiliar a caracterizar e compreender como se forma a mistura: um conjunto significativo de léxicos compartilhados assim como a incorporação de vocábulos e expressões, no exemplo do espanhol na variedade do português da fronteira; também o uso dos artigos definidos nas nomeações dos estabelecimentos comerciais, uma evidente estratégia de aproximação, visando ao "cliente" do outro lado da fronteira.

Um mapeamento descritivo do portunhol, sobretudo, portunhol língua da fronteira pode contribuir na implementação de políticas linguísticas que promovam a integração nos espaços transnacionais na América do Sul, subsidiadas no conhecimento sobre as situações linguísticas das fronteiras vivas. 


\section{Referência bibliográficas}

Albuquerque, J. L. (2014). As fronteiras do Portunhol selvagem. Revista TB, 196, 89-108. Disponível em https://bit.ly/2NOgubJ

Barrios, G. (2014). La denominación de variedades lingüísticas en situaciones de contacto: dialecto fronterizo, DPU, portugués uruguayo, portugués fronterizo o portuñol. En: Y. Hipperdinger (comp.), Lenguas: conceptos y contactos, Bahía Blanca, EdiUNS (Editorial de la Universidad Nacional del Sur), 77-105.

Camblong, A. M. (2002). Habitar la Frontera, un viaje perpetuo a lo paradójico. In Congresso Latinoamericano de Educación Intercultural Bilíngue, 6 a 9 de agosto de 2002. Lima /Peru.

Capucho, M. F. (2010). Ciência, ideologia, intervenção: a Intercompreensão para além das utopias, Synergies Europe, 5, 101-103.

Carvalho, A. M. (2003). Rumo a uma definição do português uruguaio. Revista Internacional de Linguística Iberoamericana (RILI), 1(2), 125-149.

Coutinho, B. E. (2016). A designação dos estabelecimentos comerciais na cidade fronteiriça de Uruguaiana: interface português - espanhol. Dissertação de mestrado, PPGLETRAS/ UFSM, Santa Maria. Disponível em https://bit.ly/2TyYuXa

Dicionário Compartilhado de Língua de Fronteira (2015) V1 e v2. Santa Maria: Ed. UFSM.

Documentos de la Comisión de las Políticas Linguísticas en la Educación Pública (2008). Administración Nacional Pública, Consejo Directivo Central, Montevideo.

Elizaincin, A., Barrios, G., \& Behares, L. (1987). Nos falemo brasilero. Dialectos portugueses en Uruguay. Montevideo: Amesur.

Fenner, A. L., \& Corbari, C. C. (2014). Entre falares de fronteira do Paraná: preconceito ou aceitação? Estudos Linguísticos, 43(1), 489-499.

Gonçalves, L. A. (2005). Minidicionário de Uruguaianês. A terra de longos olhares. Lucia Silva e Silva (org.), Porto Alegre: Evangraf.

Henriques, E. (2000). Intercompreensão de texto escrito por falantes nativos de Português e de Espanhol. DELTA, 16(2), 263-295.

Hensey, F. (1972). The Sociolinguistics of the Brazilian-Uruguayan Border. Den Haag, Mouton.

Lingua Mae (2015). Rivera-Uruguai: Editorial Independiente.

Lipski, J. (2011). Um caso de contato de fronteira: o sudoeste. Os contatos linguísticos no Brasil, 349-368. Cleo Altenhofen; Heloísa Mello \& Tommaso Raso (orgs.). Belo Horizonte: Ed. UFMG.

Maia, I. C. da, \& Méndez, S. C. (2018). Falantes de português missioneiro de fronteiras em Posadas PMF: o caso do bairro San Lorenzo. Web Revista SOCIODIALETO, 7(21), 152-162.

Rona, J. P. (1965). El dialecto "fronterizo" del Norte del Uruguay. Montevideo: Adolfo Linardi Editor. 
Selinker, L. (1991). La Interlengua. Juana Muñoz Liceras (org.) La Adquisición de las Lenguas Extranjeras. cap 5. Tradução de Marcelino Marcos. Madrid: Visor, Linguística y Conocimiento.

Severo, F. (2015). Discurso de Fabián Severo pronunciado en la mesa de apertura del $16^{\circ}$ Congresso Brasileiro de Professores de Espanhol. Blog espanholdobrasil. Disponível em https://bit.ly/2ZXb98L

Sturza, E. (2006). Línguas de fronteira e política de línguas: uma história das ideias linguísticas. Tese de doutorado, Instituto Estudos da Linguagem/UNICAMP, Campinas -SP.

Sturza, E. (2019). 'Portunhol’: língua, história e política, Revista Gragoatá, 24(48).

Trindade, A., Behares, L., \& Fonseca, M. (1995). Educação e linguagem em áreas da fronteira Brasil-Uruguai. Santa Maria/RS: Pallotti.

Zolin-Vesz, F. (2014). Como ser feliz em meio ao Portunhol que se produz na sala de aula: por uma pedagogia translíngue, Revista Trabalho em Linguística Aplicada, 53(2), 321-332. 